\title{
Serum NT-pro-BNP Levels Predict Cardiovascular Events in Acromegaly Patients
}

\section{(ㅇ)( $\odot \Theta$}

\author{
Authors \\ Marta Ragonese1, Gianluca Di Bella², Federica Spagnolo³, Loredana Grasso ${ }^{4}$, Angela Alibrandi ${ }^{5}$, Guiseppe Giuffrida ${ }^{2}$ \\ Mariacarla Moleti², Francesco Ferraù ${ }^{1}$, Salvatore Cannavò̀ ${ }^{1}$
}

\section{Affiliations}

1 Department of Human Pathology DETEV, University of Messina, Messina, Italy

2 Department of Clinical and Experimental Medicine, University of Messina, Messina, Italy

3 Unit of Endocrinology, University of Messina, Messina, Italy

4 Service of Immunometry and Laboratory Diagnosis, University Hospital “G. Martino”, Messina, Italy

5 Department of Economics, University of Messina, Messina, Italy

Key words

NT-pro-BNP, acromegaly, cardiovascular, prediction, mortality

published online $\quad 23.12 .2021$

Bibliography

Exp Clin Endocrinol Diabetes 2022; 130: 229-236

DOI 10.1055/a-1540-5009

ISSN 0947-7349

(c) 2021. The Author(s).

This is an open access article published by Thieme under the terms of the Creative Commons Attribution-NonDerivative-NonCommercial-License, permitting copying and reproduction so long as the original work is given appropriate credit. Contents may not be used for commecial purposes, or adapted, remixed, transformed or built upon. (https://creativecommons. org/licenses/by-nc-nd/4.0/)

Georg Thieme Verlag KG, Rüdigerstraße 14,

70469 Stuttgart, Germany

Correspondence

Marta Ragonese

UOC di Endocrinologia, Pad. $\mathrm{H}$

AOU Policlinico “G. Martino" Via C. Valeria n. 1

98125 Messina

Tel.: + 39/090/2213945

ragonese_m@yahoo.it

\section{ABSTRACT}

Background Acromegaly is associated with an increased risk of fatal and non-fatal cardiovascular (CV) events. Controlling acromegaly decreases, but does not normalize this risk. Brain natriuretic peptide (BNP) assessment is used in the general population for the diagnosis of heart failure and to predict ischemic recurrences and mortality. This is a retrospective, longitudinal, monocenter study that evaluates the role of serum $\mathrm{N}$-terminal fragment of BNP (NT-pro-BNP) for predicting CV events in acromegaly patients.

Methods Serum NT-pro-BNP levels were measured in $76 \mathrm{pa}-$ tients with acromegaly ( 23 males, $57.7 \pm 1.5$ years), and compared with other predictors of CV events. NT-pro-BNP cut-off value discriminating the occurrence of $\mathrm{CV}$ events was determined by ROC analysis. CV events were recorded during a follow-up of $78.6 \pm 6.4$ months.

Results CV events occurred in $9.2 \%$ of patients. Mean log(NTpro-BNP) concentration was higher in patients who experienced $C V$ events than in those who did not $(p<0.01)$ and in patients who died due to $C V$ events than in those who died due to other causes $(p<0.01)$. Based on the ROC curve, a cut-off value of $91.55 \mathrm{pg} / \mathrm{mL}$ could predict CV events (OR 19.06). Log(NT-proBNP) was lower in surgically treated patients by surgery $(p<0.05)$, and in those cured by neurosurgery $(p<0.02)$.

Conclusions High NT-pro-BNP value is an independent middle-term predictor of fatal or non-fatal CV events in patients with acromegaly. According to this parameter, surgically treated patients show lower CV risk than those managed with medical therapy, especially if the disease is cured. 


$\begin{array}{ll}\text { LIST OF ABBREVIATIONS } \\ \text { BNP } & \text { Brain natriuretic peptide } \\ \text { NT-pro-BNP } & \text { N-terminal fragment of BNP } \\ \text { CV } & \text { Cardiovascular } \\ \text { OSAS } & \text { Obstructive sleep apnoea syndrome } \\ \text { C-MR } & \text { Cardiac magnetic resonance } \\ \text { CT } & \text { Computed tomography } \\ \text { AS } & \text { Agatston score } \\ \text { FS } & \text { Framingham score } \\ \text { LVM } & \text { Left ventricular mass } \\ \text { EF } & \text { Ejection fraction } \\ \text { SSa } & \text { Somatostatin analogs } \\ \text { PEGV } & \text { Pegvisomant } \\ \text { ULN } & \text { Upper limit of normality } \\ \text { SE } & \text { Standard error } \\ \text { ROC } & \text { Receiver operating characteristic } \\ \text { AUROC } & \text { Area under the ROC curve } \\ \text { NPV } & \text { Negative predictive value } \\ \text { PPV } & \text { Positive predictive value } \\ \text { DA } & \text { Diagnostic accuracy } \\ \text { EAT } & \text { Epicardial adipose tissue } \\ \text { GHD } & \text { Growth hormone deficiency } \\ & \end{array}$

\section{Background}

Acromegaly is a rare endocrine disorder, due to excess of growth hormone (GH) and insulin-like growth factor (IGF)- 1 caused in most cases by pituitary tumors [1]. In addition to the typical outward manifestations, hormone hypersecretion indirectly increases morbidity and mortality, especially in individuals suffering from cardiovascular (CV) disorders and cancer [2]. The availability of enhanced diagnostic tools and new medical therapies have significantly lowered the CV risk in patients with acromegaly than in the past, at least when serum IGF-1 concentration is normalized [3]. However, especially in patients with comorbidities such as diabetes mellitus, hypertension, or obstructive sleep apnoea syndrome (OSAS), the burden of CV disease remains markedly increased, regardless of acromegaly control [4].

In this respect, the ability to identify acromegaly patients at risk for CV complications by both invasive and non-invasive approaches has improved over the years [5]. At present, bidimensional cardiac ultrasonography (c-US) is regarded as the gold standard for investigating cardiomyopathy in patients with acromegaly [6], as well as in the general population, and it should be performed at the time of disease diagnosis, and annually over the follow-up period. Although cardiac magnetic resonance (c-MR) proved to be more sensitive than c-US in diagnosing acromegaly cardiomyopathy [7], it is an expensive and not widely available technique [8]. In addition, the Agatston score (AS) is a semi-automated tool based on the calculation of the extent of coronary artery calcifications detected by unenhanced low-dose computed tomography (CT) scan [9], which demonstrates a good correlation with contrast-enhanced CT coronary angiography [10], despite its inability to detect soft non-calcified plaques. Instead, Framingham Score (FS), a gender-specific algorithm based on patient's age, lipid profile, smoking habits, and occurrence of hypertension, is used to predict the long-term (10 years) risk of hard coronary heart disease and cerebrovascular events in the general population [11]. Both FS and AS have been shown to be suitable markers for evaluating middle term (5 years) risk of CV events in patients with acromegaly $[5,6]$.

Brain natriuretic peptide (BNP) is a hormone produced by ventricular cardiomyocytes and released into the circulation in response to volumetric or pressure ventricular wall overload [12]. Elevated levels of the N-terminal fragment of its pro-hormone (NT-pro-BNP) are used to differentiate cardiac from pulmonary causes of acute heart failure [13], assess the severity of chronic heart failure [14, 15], and predict ischemic recurrences and short- or long-term CV mortality $[16,17]$. Studies exploring the role of NT-pro-BNP as a predictor of $\mathrm{CV}$ events in acromegaly patients have yielded conflicting results. One study concluded that NT-pro-BNP is not a reliable indicator of cardiac dysfunction in acromegaly patients, because no correlation between c-US parameters and this biochemical marker could be demonstrated [18]. By contrast, Andreassen et al. found an inverse association of circulating levels of both BNP and NT-pro-BNP with ventricular ejection fraction (EF), and positive association with left ventricular mass (LVM) evaluated by c-MR, thus suggesting that Btype natriuretic peptides are markers of cardiac dysfunction [19]. Recently, Eichner et al. demonstrated a significant relationship between IGF-1 and changes in NT-pro-BNP levels but no associations with LVM index, suggesting a different effect of acromegaly on CV parameters [20]. Although most of the studies support the role of NT-pro-BNP in the prediction of major CV and cerebrovascular events for the general population, its predictive role in patients with acromegaly is poorly documented.

The aim of our study was to evaluate the role of serum NT-proBNP levels to predict the middle-term risk of cardiovascular events in acromegaly patients and compare it with demographic and clinical characteristics and other surrogate markers of cardiovascular function.

\section{Methods}

This was a retrospective longitudinal single-institution study including 76 subjects ( 23 men and 53 women; mean age at the time of diagnosis of acromegaly was $47.3 \pm 1.5$ years; mean age at the time of evaluation was $57.7 \pm 1.5$ years) referred to our Endocrine Unit from 2000 to 2012. Acromegaly was diagnosed in all cases in accordance with the guidelines in use at the time of diagnosis.

Pituitary macroadenoma was demonstrated in 49/76 (64.5\%) cases and microadenoma in the remaining 27 (35.5\%) cases. All treatments undertaken by patients are mentioned in > Fig. 1 . Among medically treated patients, 47 received first-generation somatostatin analogs (SSa), 10 received pegvisomant (PEGV), and 12, both SSa and PEGV.

Serum GH and IGF-1 levels were measured by immunoradiometric assay, using commercial kits (Immulite 1000 Immunoassay System, Siemens). The sensitivity threshold values for GH and IGF-I values were 0.04 and $6 \mathrm{ng} / \mathrm{mL}$, respectively. The intra- or the inter-assay coefficients of variation, for each assay, were $<5 \%$ and $<10 \%$, respectively. The range of normality for serum IGF-I levels was calculated in 485 healthy subjects. Serum IGF-I normal values for subjects aged 


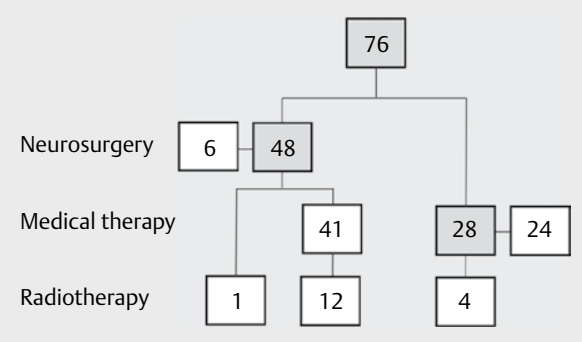

Fig. 1 Therapies performed by patients during the follow-up. Among the 76 patients, 48 underwent surgery (alone, $n=6$; followed by radiotherapy, $n=1$; medical therapy, $n=29$, or by both medical therapy and radiotherapy, $n=12$ ), while 28 patients underwent first-line medical treatment (alone, $n=24$, or followed by radiotherapy, $n=4)$.

$21-35,36-50$, and 51-75 years were $115-358,94-284$, and 64$238 \mathrm{ng} / \mathrm{mL}$, respectively. Serum IGF-1 levels were expressed in $\mathrm{ng} /$ $\mathrm{mL}$ and as the upper limit of normality (xULN). According to the most recent consensus statement on acromegaly, the disease was considered adequately controlled when IGF- 1 levels were $\leq 1.0$ xULN and random $\mathrm{GH}<1.0 \mathrm{ng} / \mathrm{mL}$. For patients treated with PEGV, the disease was considered controlled only on the basis of IGF-1 values [21].

Serum NT-pro-BNP level was measured by chemiluminescent enzyme immunoassay (Immulite 2000 system, Siemens). The sensitivity threshold of the NT-pro-BNP assay was $5.0 \mathrm{pg} / \mathrm{mL}$. The intraor the inter-assay coefficients of variation were $<2 \%$ and $<5 \%$, respectively. Skilled technical personnel performed all assays according to the manufacturers' recommendations. The normal reference range of NT-pro-BNP was $<110 \mathrm{pg} / \mathrm{mL}$.

Furthermore, FS was calculated in all patients to estimate the 10year CV risk, using an interactive tool (https://framinghamheartstudy.org/fhs-risk-functions/cardiovascular-disease-10-year-risk/) based on a specific algorithm which integrates the following parameters: sex, age, systolic blood pressure, hypertension treatment, smoking habit, diabetes, HDL, and total cholesterol values [11].

Patients were followed up for $78.6 \pm 6.4$ months. During this period, they underwent conventional clinical, instrumental and biochemical evaluation, to monitor response to specific treatments, acromegaly complications, and cardiometabolic profile [22]. Patients gave their informed consent to the procedures and to the study, which was approved by the local ethical committee of our university hospital.

\section{Statistical analysis}

Numerical data are expressed as mean \pm standard error (SE) and categorical variables as numbers and percentages. Since examined variables were not normally distributed (Kolmogorov Smirnov test), the non-parametric approach was used. NT-pro-BNP values were log-transformed [log(NT-pro-BNP)] and compared by Mann Whitney test in patients with versus those without CV events (both fatal and non-fatal), and in dead versus alive patients.

To determine the optimal NT-pro-BNP cut-off value, and to discriminate the presence/absence of CV events in the entire cohort of patients, a Receiver Operating Characteristic (ROC) curve was realized, and the area under the curve (AUROC) was calculated along with the relative $95 \%$ Confidence Interval $(95 \% \mathrm{Cl})$ and significance. Sensitivity, specificity, negative predictive value (NPV), positive predictive value (PPV), and diagnostic accuracy (DA) were evaluated for the cut-off individuated through the ROC analysis.

Logistic univariate regression models were estimated to assess the possible dependence of CV events on some potential explicative variables [clinical features, including gender, age, age at diagnosis, tumor dimension, therapies, duration of active disease (calculated from the presumed onset of symptoms), BMI, presence of OSAS, arterial hypertension, systolic and diastolic blood pressure values, smoking habit; biochemical parameters, including serum GH and IGF- 1 levels, IGF- 1 xULN values, serum NT-pro-BNP levels; type 2 diabetes mellitus, hypercholesterolemia, hypertriglyceridemia, and overall deaths]. Variables with $p$-value $<0.05$ at univariate analysis were then subjected to multivariate analysis and included in the model to identify independent predictive factors of CV events.

Logistic univariate regression models were also estimated to assess the possible dependence of NT-pro-BNP on clinical (patients' age and BMI) and echocardiography parameters (interventricular septum, end-diastolic diameter, ejection fraction, left ventricular mass, and E/A ratio).

Finally, Kaplan-Meier curves were realized to quantify the survival time until the occurrence of any CV event, both in the entire group of patients and after stratification for gender and the NT-pro-BNP cut-off was identified by ROC curve analysis. The curves related to different groups were then compared using the Log rank test.

Statistical analyses were performed using SPSS 20.0 for the Window package. A p-value $<0.05$ was considered to be statistically significant.

\section{Results}

\section{Clinical characteristics}

The demographic and clinical characteristics of patients enrolled in this study are mentioned in $>$ Table 1.

At baseline, 47/76 (61.8\%) patients showed disease control; of these, $40 / 47$ (85.1\%) were under medical therapy, six patients (12.8\%) had surgery alone, and one patient (2.1\%) had surgery as well as radiosurgery. Serum GH levels and IGF- 1 x ULN values were lower in patients with controlled disease than those in the other patients (GH: $0.5 \pm 0.05$ vs $2.3 \pm 0.4 \mathrm{ng} / \mathrm{mL}, \mathrm{p}<0.02$; IGF- 1 : $0.7 \pm 0.02$ vs $1.6 \pm 0.2 x U L N, p<0.005)$ ( $\triangleright$ Table 2 ).

Six patients were lost to follow-up due to death (three, CV diseases; one malignancy; two, other causes), and the other four experienced non-fatal CV events. Overall, the prevalence of CV events in patients was $9.2 \%$, with no differences between patients with uncontrolled and controlled acromegaly (2/29 vs 5/47, p NS). The mean age of patients who experienced CV events was not significantly different from that of the other ones $(62.3 \pm 3.6$ vs $57.1 \pm 1.6$ years, $\mathrm{p} N \mathrm{NS})$.

\section{Cardiovascular risk evaluation}

Mean FS was not significantly different between patients with active acromegaly compared to those with controlled disease 
- Table 1 Demographic, clinical, biochemical, and radiological characteristics of all patients with acromegaly at baseline evaluation.

\begin{tabular}{|c|c|}
\hline Patients (no.) & 76 \\
\hline Male/Female (no.) & $23 / 53$ \\
\hline Age (years) & $57.7 \pm 1.5$ \\
\hline BMI $\left(\mathrm{Kg} / \mathbf{m}^{2}\right)$ & $29.2 \pm 0.5$ \\
\hline Current or past smokers (no.) & 29 \\
\hline Age at diagnosis (years) & $47.3 \pm 1.5$ \\
\hline Estimated duration of active acromegaly (years) & $7.4 \pm 0.8$ \\
\hline $\begin{array}{l}\text { Pituitary tumour dimension (macro/microadeno- } \\
\text { ma) (no) }\end{array}$ & $49 / 27$ \\
\hline Controlled/active acromegaly at baseline (no.) & $47 / 29$ \\
\hline Medical therapy (no.) & 69 \\
\hline Radiotherapy (no.) & 17 \\
\hline Neurosurgery (no.) & 48 \\
\hline $\mathrm{GH}(\mathrm{ng} / \mathrm{mL})$ & $2.2 \pm 0.3$ \\
\hline IGF-1 (ng/mL) & $160.3 \pm 9.3$ \\
\hline IGF-1 xULN & $0.7 \pm 0.04$ \\
\hline NT-pro-BNP (pg/mL) & $216.14 \pm 99.4$ \\
\hline $\log ($ NT-pro-BNP) & $1.6 \pm 0.06$ \\
\hline Arterial hypertension (no.) & 48 \\
\hline Type 2 diabetes mellitus (no.) & 21 \\
\hline Dyslipidemia (no.) & 26 \\
\hline OSAS (no.) & 17 \\
\hline \multicolumn{2}{|c|}{$\begin{array}{l}\text { BNP: brain natriuretic peptide; BMI: basal metabolic index; GH: growth } \\
\text { hormone; OSAS: obstructive sleep apnea syndrome; FS: Framingham } \\
\text { score; IGF-1: insulin-like growth factor-1; ULN: upper limit of normality }\end{array}$} \\
\hline
\end{tabular}

- Table 2 Clinical and biochemical parameters of patients with controlled and active acromegaly. The number of patients with fatal or non-fatal cardiovascular (CV) events, occurring during the follow-up, is also mentioned in this table.

\begin{tabular}{|l|l|l|l|}
\hline & $\begin{array}{l}\text { Patients with } \\
\text { controlled } \\
\text { acromegaly }\end{array}$ & $\begin{array}{l}\text { Patients with } \\
\text { active } \\
\text { acromegaly }\end{array}$ & p-value \\
\hline Patients (no.) & 47 & 29 & \\
\hline GH (ng/mL) & $0.5 \pm 0.05$ & $2.3 \pm 0.4$ & $<\mathbf{0 . 0 1}$ \\
\hline IGF-1 xULN & $0.7 \pm 0.02$ & $1.6 \pm 0.2$ & $<\mathbf{0 . 0 1}$ \\
\hline NT-pro-BNP (pg/mL) & $115.7 \pm 48.9$ & $1072.2 \pm 823.9$ & NS \\
\hline log(NT-pro-BNP) & $1.5 \pm 0.06$ & $1.8 \pm 0.1$ & NS \\
\hline Framingham score & $11.02 \pm 0.8$ & $12.5 \pm 1.08$ & NS \\
\hline $\begin{array}{l}\text { Patients with CV } \\
\text { events (no.) }\end{array}$ & 5 & 2 & NS \\
\hline $\begin{array}{l}\text { BNP: brain natriuretic peptide; CV: cardiovascular: IGF-1: insulin-like } \\
\text { growth factor-1; ULN: upper limit of normality * Excluding patients } \\
\text { treated with Pegvisomant }\end{array}$ \\
\hline
\end{tabular}

$(12.5 \pm 1.08$ vs $11.02 \pm 0.8$, p NS) ( $\triangleright$ Table 2$)$, or between patients who experienced $C V$ events and those who did not ( $13.7 \pm 1.5$ vs $11.3 \pm 0.7$, p NS).

Overall, the mean log(NT-pro-BNP) value was higher, although not significantly, in patients with uncontrolled acromegaly than in other patients $(1.8 \pm 0.1$ vs $1.5 \pm 0.06, p=0.06)$ ( ever, the value was significantly lower in patients treated by sur-

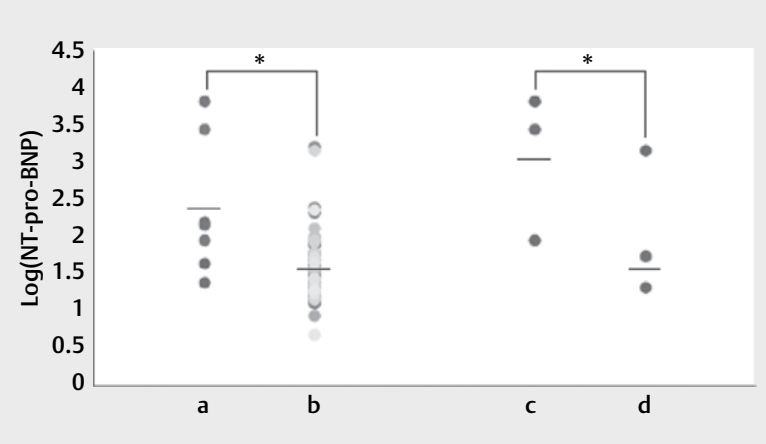

- Fig. 2 Log(NT-pro-BNP) values in each patient who experienced cardiovascular (CV) events a versus the other patients $\mathbf{b}$, and in each patient who died for $\mathrm{CV}$ events $\mathbf{c}$, versus the patients who died due to other causes d; mean $\log (\mathrm{NT}$-pro-BNP) values are expressed for each group of patients (_). ${ }^{*} \mathrm{p}<0.01$.

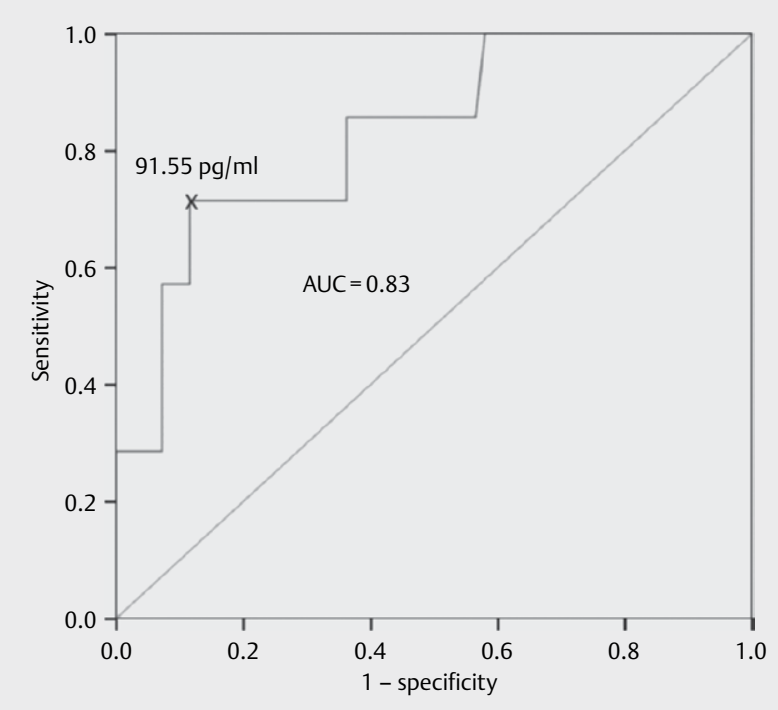

- Fig. 3 ROC curve represents the sensitivity $(71.4 \%)$ and specificity $(88.4 \%)$ of serum NT-pro-BNP cut-off value $=91.55 \mathrm{pg} / \mathrm{mL}$ to predict cardiovascular events in acromegaly patients. $\mathrm{AUC}=0.83$ with confidence interval 0.67-0.99.

gery alone or followed by medical therapy, than in the patients managed only with medical treatment $(1.4 \pm 0.09$ vs $1.8 \pm 0.1$, $\mathrm{p}<0.02 ; 1.5 \pm 0.07$ vs $1.8 \pm 0.1, \mathrm{p}<0.05)$, and in patients cured by neurosurgery than in those still active thereafter $(1.4 \pm 0.04$ vs $1.6 \pm 0.07, p<0.02)$. However, when we excluded patients treated by surgery from the analysis, log(NT-pro-BNP) values were higher in patients with active disease than in those with controlled acromegaly. No difference was observed among patients treated with different drugs.

Mean log(NT-pro-BNP) concentration was significantly higher in patients who experienced $\mathrm{CV}$ events than in other patients $(2.4 \pm 0.9$ vs $1.6 \pm 0.4, \mathrm{p}<0.01)$ and in patients who died due to $C V$ events than in those who died due to other causes $(3.08 \pm 0.9$ vs $1.6 \pm 0.4, p<0.01$ ) ( $\vee$ Fig. 2). 
- Table 3 Characteristics of patients enrolled in this study. Patients were categorized on the basis of NT-pro-BNP cut-off value detected by ROC curve.

\begin{tabular}{|c|c|c|c|}
\hline NT-pro-BNP values (pg/mL) & $<91.55$ & $>91.55$ & $p$ \\
\hline Patients (no). & 63 & 13 & \\
\hline$M / F$ & $18 / 45$ & $5 / 8$ & NS \\
\hline Age (years) & $55.2 \pm 1.6$ & $69.9 \pm 1.6$ & $<0.02$ \\
\hline BMI $\left(\mathrm{Kg} / \mathrm{m}^{2}\right)$ & $29.7 \pm 0.6$ & $28.9 \pm 1.3$ & NS \\
\hline Age at diagnosis (years) & $44.7 \pm 1.6$ & $60.5 \pm 2.3$ & $<0.02$ \\
\hline $\begin{array}{l}\text { Estimated duration of } \\
\text { active disease (years) }\end{array}$ & $7.8 \pm 0.9$ & $10.9 \pm 2.2$ & $=0.05$ \\
\hline $\begin{array}{l}\text { Pituitary tumour (macro/ } \\
\text { microadenomas) }\end{array}$ & $43 / 20$ & $7 / 6$ & NS \\
\hline GH (ng/mL) & $2.1 \pm 0.4$ & $2.6 \pm 0.8$ & NS \\
\hline IGF-1 (ng/mL) & $160.1 \pm 10.3$ & $142.4 \pm 12.6$ & NS \\
\hline IGF-1 xULN & $0.7 \pm 0.04$ & $0.8 \pm 0.07$ & NS \\
\hline $\begin{array}{l}\text { Patients with controlled/ } \\
\text { active disease (no.) }\end{array}$ & $40 / 23$ & $7 / 6$ & NS \\
\hline $\begin{array}{l}\text { Medical therapies (SSa/ } \\
\text { Peg/SSa + Peg) }\end{array}$ & $56(37 / 8 / 11)$ & $13(10 / 2 / 1)$ & NS \\
\hline Radiotherapy (no.) & 14 & 3 & NS \\
\hline Neurosurgery (no.) & 43 & 5 & $<0.05$ \\
\hline NT-pro-BNP (pg/mL) & $33.5 \pm 2.6$ & $618.9 \pm 256.5$ & $<0.05$ \\
\hline $\log (\mathrm{NT}-\mathrm{pro}-\mathrm{BNP})$ & $1.4 \pm 0.03$ & $2.4 \pm 0.1$ & $<0.02$ \\
\hline Hypertension (no.) & 37 & 11 & NS \\
\hline $\begin{array}{l}\text { Diabetes mellitus type } 2 \\
\text { (no.) }\end{array}$ & 19 & 2 & NS \\
\hline Dyslipidemia (no.) & 23 & 3 & NS \\
\hline OSAS (no.) & 15 & 2 & NS \\
\hline $\begin{array}{l}\text { Smokers and ex-smokers } \\
\text { (no.) }\end{array}$ & 25 & 4 & NS \\
\hline Total deaths (no.) & 2 & 4 & $<0.001$ \\
\hline $\begin{array}{l}\text { Fatal cardiovascular events } \\
\text { (no.) }\end{array}$ & 0 & 3 & $<0.001$ \\
\hline $\begin{array}{l}\text { Non-fatal cardiovascular } \\
\text { events (no.) }\end{array}$ & 2 & 2 & $=0.07$ \\
\hline \multicolumn{4}{|c|}{$\begin{array}{l}\text { BNP: brain natriuretic peptide; BMI: basal metabolic index; GH: growth } \\
\text { hormone; OSAS: obstructive sleep apnea syndrome; FS: Framingham } \\
\text { score; IGF-1: insulin-like growth factor-1; ULN: upper limit of normality; } \\
\text { SSa: somatostatin analogues; Peg: Pegvisomant }\end{array}$} \\
\hline
\end{tabular}

Based on the ROC curve analysis, the best cut-off value of serum NT-pro-BNP levels predicting CV events in acromegaly patients was $91.55 \mathrm{pg} / \mathrm{mL}$, with a sensitivity of 0.714 , specificity of 0.884 , PPV of 0.385 , NPV of 0.968 , and DA of 0.868 ( Fig. 3). Patients with serum NT-pro-BNP values $>91.55 \mathrm{pg} / \mathrm{mL}$ showed significantly higher mean age, estimated duration of active disease, than the others in addition to more number of deaths. Among seven patients who experienced CV events, five showed serum NT-pro-BNP levels $>91.55 \mathrm{pg} / \mathrm{mL}$ (OR 19.06), and in three cases the CV event was fatal ( $\triangleright$ Table 3 ).

Logistic univariate regression analysis showed a significantly positive association of CV events with male gender (OR 7.1; $95 \%$ C.I. 1.26 - 39.78; $p=0.026$ ), hypertriglyceridemia (OR 8.8; $95 \%$ C.I. $1.18-65.47 ; p=0.034$ ) and, as a continuous variable, with 10 -years
- Table. 4 Linear univariate regression analysis: clinical and biochemical characteristics of patients with acromegaly according to cardiovascular events

\begin{tabular}{|c|c|c|}
\hline & OR (confidence interval) & p-value \\
\hline Gender & $7.083(1.261-39.780)$ & 0.026 \\
\hline Age & $1.048(0.976-1.124)$ & 0.195 \\
\hline BMI & $0.171(0.832-1.159)$ & 0.473 \\
\hline Age at diagnosis & $1.026(0.965-1.091)$ & 0.411 \\
\hline Years of active disease & $1.049(0.955-1.153)$ & 0.313 \\
\hline Tumor dimension & $0.375(0.077-1.818)$ & 0.223 \\
\hline Systolic blood pressure & $1.019(0.974-1.066)$ & 0.412 \\
\hline Diastolic blood pressure & $1.067(0.974-1.170)$ & 0.164 \\
\hline Arterial hypertension & $4.610(0.537-39.608)$ & 0.164 \\
\hline Type 2 diabetes mellitus & $0.408(0.046-3.612)$ & 0.421 \\
\hline Hypercholesterolemia & $1.602(0.330-7.781)$ & 0.559 \\
\hline Hypertriglyceridemia & $8.800(1.183-65.475)$ & 0.034 \\
\hline OSAS & $2.154(0.246-18.844)$ & 0.488 \\
\hline Smoking habit & $2.347(0.486-11.340)$ & 0.289 \\
\hline $\mathrm{GH}^{*}$ & $0.909(0.646-1.280)$ & 0.584 \\
\hline IGF-1 ng/mL & $1.001(0.992-1.010)$ & 0.825 \\
\hline IGF-1 xULN & $1.823(0.338-9.827)$ & 0.485 \\
\hline Acromegaly control & $0.787(0.084-7.403)$ & 0.834 \\
\hline Neurosurgery & $0.200(0.036-1.111)$ & 0.066 \\
\hline Radiotherapy & $2.946(0.590-14.708)$ & 0.188 \\
\hline Somatostatin analogues & $0.339(0.068-1.694)$ & 0.188 \\
\hline Pegvisomant & $3.778(0.770-18.534)$ & 0.101 \\
\hline Framingham score & $1.092(0.927-1.285)$ & 0.293 \\
\hline FS 10-year risk & $1.194(1.044-1.367)$ & 0.010 \\
\hline NT-pro-BNP (pg/mL) & $1.001(1.000-1.003)$ & 0.044 \\
\hline $\log ($ NT-pro-BNP) & $6.396(1.874-21.826)$ & 0.003 \\
\hline NT-pro-BNP\# & $19.062(3.158-115.071)$ & 0.001 \\
\hline NT-pro-BNP§ & $11.810(2.182-63.916)$ & 0.004 \\
\hline \multicolumn{3}{|c|}{$\begin{array}{l}\text { BNP: brain natriuretic peptide; BMI: basal metabolic index; OSAS: } \\
\text { obstructive sleep apnea syndrome; FS: Framingham score; IGF-1: } \\
\text { insulin-like growth factor-1; ULN: upper limit of normality; * Excluding } \\
\text { patients treated with Pegvisomant; \# increased/normal values according } \\
\text { to the cut-off detected by ROC curve; } \S \text { increased/normal values } \\
\text { according to the local reference normal range calculated in the general } \\
\text { population }\end{array}$} \\
\hline
\end{tabular}

risk score at FS (OR 1.2, $95 \%$ C.I. 1.04 - 1.36; $p=0.010)$, log(NT-proBNP) values (OR 6.4; $95 \%$ C.I. 1.87 - 21.82; $p=0.003$ ), NT-pro-BNP above 1 x ULN (OR 11.8, 95\% C.I. 2.18 - 63.91; $\mathrm{p}=0.004$ ), and above the cut-off detected by ROC curve (OR 19.06; $95 \%$ C.I. 3.15 115.07; $p=0.001$ ) ( $>$ Table 4). Nevertheless, in the multivariate regression analysis, only the last two variables were observed to be independently associated with CV events (OR 10.3, $p<0.033$, and OR 20.7, p 0.009, respectively).

Logistic univariate regression analysis also showed a positive correlation of NT-pro-BNP with age (OR 0.02; $95 \%$ C.I. 0.010 0.028; $\mathrm{p}<0.01$ ) but not with BMI (OR 0.01; $95 \%$ C.I. -0.025 - 0.027 , p NS). No echocardiography parameters correlated with NT-proBNP values (p NS). 
The Kaplan Meier curves demonstrated that the "event-freesurvival" was significantly shorter in men than in women $(p<0.02)$, and in patients with serum NT-pro-BNP values $>91.55 \mathrm{pg} / \mathrm{mL}$ than in the other patients $(p<0.001)$.

\section{Discussion}

In this study, we found the occurrence of a CV event in $9.2 \%$ of our patient cohort with acromegaly, with a mortality rate of $43 \%$, during a mean follow-up of 6.5 years. The CV events were not associated either with disease activity, or with increased FS score, but the risk of developing a CV event was 19 times greater in patients with serum NT-pro-BNP levels above $91.55 \mathrm{pg} / \mathrm{mL}$, based on the ROC curve analysis. Accordingly, patients who experienced CV events showed NT-pro-BNP concentrations significantly higher than the other patients. In addition, the univariate regression analysis showed a positive dependence of $C V$ events also on the male gender, hypertriglyceridemia and, to a less extent, on increased FS, the multivariate analysis confirmed a significant dependence only on serum NT-pro-BNP levels above 1 x ULN or above the cut-off value demonstrated by the ROC curve analysis.

Particularly, although the identified cut-off value was within the normal reference range it was calculated for the general population, regardless of their predictive role for CV risk, and was based on ROC curve analysis in correlation with CV outcome.

In a previous study, we demonstrated that the combined evaluation of FS and AS could predict an increased risk for CV events in $41 \%$ of our acromegaly patients and that coronary calcifications could be detected in half of these patients [5]. More recently, Aulinas et al. proposed the use of the combined evaluation of epicardial adipose tissue (EAT) index and serum cystatin levels, as a surrogate marker of coronary and CV risk in acromegaly patients [23]. It is noteworthy, however, that the evaluation of NT-pro-BNP concentration is less expensive and widely available than AS and EAT, which are assessed by cardiac CT. Indeed, measurement of serum BNP or the more specific NT-pro-BNP value is currently used to evaluate cardiac dysfunction, and to predict mortality risk for CV events in the general population [12-17, 24].

Recently, Eichner et al. investigated the relationship between serum IGF-1 levels and NT-pro-BNP concentrations in the general population and found a sex-specific association between these parameters [20]. Indeed, higher IGF-1 levels and IGF-1/IGFBP-3 ratio were associated were higher NT-pro-BNP values in women, while a U-shaped relation of baseline IGF-1, IGFBP-3, and IGF-1/IGFBP-3 ratio with increased NT-pro-BNP levels was observed in men. Data on BNP or NT-pro-BNP concentrations, and their role in the evaluation of cardiovascular status, are scanty and conflicting in patients with abnormalities in the GH/IGF-1 axis. In a study published by Arikan et al. in 2010, serum NT-pro-BNP values were found to be slightly higher in naïve acromegaly patients than in controls [18]. However, other studies did not confirm this finding. A few studies observed similar NT-pro-BNP levels among patients with active or controlled acromegaly and healthy subjects [25, 26], or an inverse correlation between serum IGF- 1 and BNP levels in acromegaly patients evaluated after pituitary surgery, and with normal left ventricular systolic function and dimensions [27]. Other studies demonstrated an increase in serum NT-pro-BNP levels during somato- statin analogs therapy, probably indicating an initial impairment of cardiac function [19,28]. Conversely, Potter et al. found no significant changes in NT-pro-BNP levels during medical treatment [25]. Nevertheless, the differences among the findings of these studies are probably related to the small dimension of the casuistries, and/or to the non-homogeneous status of cardiac function and morphology of the patients. On the other hand, several studies demonstrated a significant increase of NT-pro-BNP levels in patients with GHD, together with a significant decrease during $\mathrm{GH}$ replacement, associated with the improvement of $C V$ performances [28-30].

In our study, serum NT-pro-BNP levels did not correlate with IGF-1 levels or acromegaly control, based on criteria proposed by the most recent guidelines [21]. Nevertheless, if the definition of disease control was based only on IGF-1 normalization, the rate of controlled patients reached up to $88 \%$, and NT-pro-BNP levels correlated with disease control.

IGF-1 levels could be lower in the cohort with NT-pro-BNP over $91.55 \mathrm{pg} / \mathrm{mL}$ just because of the physiological reduction of IGF-1 levels with age and were found to be higher in these patients as compared to those with NT-pro-BNP lower than the identified cutoff. Indeed, IGF-1 x ULN values were similar between the two groups. On the other hand, the role of the age of the patients could be less relevant than the estimated duration of active disease, which was significantly higher in patients with NT-pro-BNP over $91.55 \mathrm{pg} / \mathrm{mL}$ in terms of impact on CV outcome.

With regard to the impact of disease management, we found lower NT-pro-BNP concentrations in patients who underwent pituitary surgery, irrespective of disease control achievement. Our data are in agreement with studies showing a reduced CV risk in acromegaly patients treated by surgery. In fact, some authors reported an increase in CV risk in patients effectively treated with SSa, but not in those cured by surgery [31]. This finding could be explained on the basis of worsened glucose tolerance during SSa treatment, irrespective of disease control, demonstrated by some studies [25, 32]. However, it is in contrast with the study by Ito et al. who showed an inverse relationship between IGF-1 and NT-proBNP in operated patients, and by Verhelst et al. who did not find any difference in NT-pro-BNP values between patients cured by surgery or those with a controlled disease by medical therapies $[26,27]$. On the other hand, Colao et al. showed a similar improvement in the ventricular hypertrophy 12 months after SSa or surgical first-line treatment, but a more pronounced improvement of systolic function in SSa-treated patients [33]. Some discrepancies among different studies could be because of the evaluation of a small number of patients by most researchers. In addition, the patients with higher CV risk were possibly treated more conservatively, with first-line SSa, rather than being proposed for neurosurgery.

Our study has some limitations, including its retrospective nature, and the small number of CV events. Nevertheless, we evaluated a wide and homogeneous group of patients, who were followed up at the same center for at least 12 months.

\section{Conclusions}

In conclusion, this study suggests that a high NT-pro-BNP value is an independent middle-term predictor of fatal or non-fatal CV 
events in patients with acromegaly. Based on this parameter, surgically treated patients show lower CV risk than those managed with medical therapy, especially if the disease is cured. The assessment of NT-pro-BNP concentration is easily feasible and can integrate other surrogate markers such as AS and FS, or imaging investigation such as c-US or c-MR, for improving the evaluation of survival expectancy. The role of NT-pro-BNP in the longitudinal evaluation of the $\mathrm{CV}$ risk assessment in acromegaly patients deserves further investigation.

\section{Declarations}

Ethics approval and consent to participate Patients gave their informed consent to the procedures and to the study, which was approved by the local ethical committee of the university hospital "Gaetano Martino" of Messina (protocol n. 560 of January 13, 2020).

Availability of data and materials All data generated or analyzed during this study are included in this published article and its supplementary information files

\section{Funding}

The study was supported by the project PRIN 2015 (number 2015ZHKFTA) of the Italian Ministry of Education, University and Research, through research grants.

\section{Author contributions}

MR, SC, MM, FF, FS, and GG analyzed and interpreted patient data, GDB performed CV examinations, LG performed biochemical analysis, AA performed the statistical analysis and interpreted related results, MR, MM, and SC were the major contributors in writing the manuscript. All authors read and approved the final manuscript.

\section{Conflict of Interests}

The authors declare that they have no competing interests

\section{References}

[1] Crisafulli S, Luxi N, Sultana J et al. Global epidemiology of acromegaly: a systematic review and meta-analysis. Eur J Endocrinol 2021: EJE-21-0216.R1. doi: 10.1530/EJE-21-0216. Epub ahead of print. PMID: 34061771

[2] Melmed S. Medical progress: acromegaly. N Engl J Med 2006; 355 : 2558-2573

[3] Bolfi F, Neves AF, Boguszewski CL, Nunes-Nogueira VS. Mortality in acromegaly decreased in the last decade: a systematic review and meta-analysis. Eur J Endocrinol 2018; 179: 59-71

[4] Gatto F, Campana C, Cocchiara F et al. Current perspectives on the impact of clinical disease and biochemical control on comorbidities and quality of life in acromegaly. Rev Endocr Metab Dis 2019; 20: 365-381
[5] Cannavò S, Almoto B, Cavalli G et al. Acromegaly and coronary disease: an integrated evaluation of conventional coronary risk factors and coronary calcifications detected by computed tomography. J Clin Endocrinol Metab 2006; 91: 3766-3772

[6] Ragonese M, Alibrandi A, Di Bella G et al. Cardiovascular events in acromegaly: distinct role of Agatston and Framingham score in the 5-year prediction. Endocrine 2014; 47: 206-212

[7] Colao A, Marzullo P, Di Somma C, Lombardi G. Growth hormone and the heart. Clin Endocrinol 2001; 54: 137-154

[8] Bogazzi F, Lombardi M, Strata E et al. High prevalence of cardiac hypertophy without detectable signs of fibrosis in patients with untreated active acromegaly: an in vivo study using magnetic resonance imaging. Clin Endocrinol 2008; 68: 361-368

[9] Agatston AS, Janowitz WR, Hildner FJ et al. Quantification of coronary artery calcium using ultrafast computed tomography. J Am Coll Cardiol 1990; 15: 827-832

[10] Ahmed W, de Graaf MA, Broersen A et al. Automatic detection and quantification of the agatston coronary artery calcium score on contrast computed tomography angiography. Int ] Cardiovasc Imaging 2015; 31: 151-161

[11] D’Agostino RB Sr, Vasan RS, Pencina MJ et al. General cardiovascular risk profile for use in primary care: the Framingham Heart Study. Circulation 2008; 117: 743-753

[12] Hess G, Moecks ], Zdunek D. N-terminal-proBNP (NT-proBNP) as an indicator of cardiac dysfunction. A study in patients with suspected cardiac disorders. ZS Kardiologie 2005; 94: 247-254

[13] Nielsen LS, Svanegaard J, Klitgaard NA, Egeblad H. N-terminal pro-brain natriuretic peptide for discriminating between cardiac and non-cardiac dyspnoea. Eur J Heart Fail 2004; 6: 63-70

[14] Maisel AS, Krishnaswamy P, Nowak RM et al. Rapid measurement of B-type natriuretic peptide in the emergency diagnosis of heart failure. N Engl J Med 2002; 347: 161-167

[15] Mukoyama M, Nakao K, Saito Y et al. Increased human brain natriuretic peptide in congestive heart failure. N Engl J Med 1990; 323: 757-758

[16] de Lemos JA, Morrow DA, Bentley JH et al. The prognostic value of B- type natriuretic peptide in patients with acute coronary syndromes. N Engl J Med 2001; 345: 1014-1021

[17] Morrow DA, de Lemos JA, Sabatine MS et al. Evaluation of B-type natriuretic peptide for risk assessment in Unstable Angina/Non-ST elevation myocardial infarction: B-type natriuretic peptide and prognosis in TAC TICS-TIMI 18. J Am Coll Cardiol 2003; 41: 1264-1272

[18] Arikan S, Bahceci M, Tuzcu A, Gokalp D. N-terminal pro-brain natriuretic peptide in newly diagnosed acromegaly. J Endocrinol Invest 2010; 33: 571-575

[19] Andreassen M, Faber J, Kjær A, Petersen CL, Kristensen LØ. Cardiac effects of 3 months treatment of acromegaly evaluated by magnetic resonance imaging and B-type natriuretic peptides. Pituitary 2010; 13: 329-336

[20] Eichner M, Wallaschofski H, Schminke U et al. Relation of IGF-1 with subclinical cardiovascular markers including intima-media thickness, left ventricular mass index and NT-proBNP. Eur J Endocrinol 2020; 182: 79-90

[21] Melmed S, Bronstein MD, Chanson P et al. A consensus statement on acromegaly therapeutic outcomes. Nat Rev Endocrinol 2018; 14: 552-561

[22] Melmed S, Casanueva FF, Klibanski A et al. A consensus on the diagnosis and treatment of acromegaly complications. Pituitary 2013; 16: 294-302

[23] Aulinas A, Crespo I, Viladés D et al. Cystatin-C and epicardial adipose tissue as noninvasive predictors of cardiovascular risk in acromegaly. Clin Endocrinol 2017; 86: 214-222

[24] Campbell DJ. Can measurement of B-type natriuretic peptide levels improve cardiovascular disease prevention? Clin Exp Pharmacol P 2008; 35: 442-446 
[25] Potter B], Beauregard C, Serri O. Serum markers of cardiovascular risk in patients with acromegaly before and after six months of treatment with octreotide LAR. Pituitary 2008; 11: 49-53

[26] Verhelst J, Velkeniers B, Maiter D et al. Active acromegaly is associated with decreased hs-CRP and NT-proBNP serum levels: insights from the Belgian registry of acromegaly. Eur J Endocrinol 2013; 168: 177-184

[27] Ito M, Kodama M, Tsumanuma I et al. Relationship between insulin-like growth factor-I and brain natriuretic peptide in patients with acromegaly after surgery. Circulation 2007; 71: 1955-1957

[28] Andreassen M, Faber J, Vestergaard H et al. N-terminal pro-B-type natriuretic peptide in patients with growth hormone disturbances. Clin Endocrinol 2007; 66: 619-625

[29] Wallaschofski H, Saller B, Spilcke-Liss E et al. Effects of growth hormone treatment on B-type natriuretic peptide as a marker of heart failure in adults with growth hormone deficiency. Horm Metab Res 2006; 38: 656-661
[30] Gruson D, Alexopoulou O, Pasquet A et al. Impact of growth hormone $(\mathrm{GH})$ treatment on circulating NT-proBNP concentrations and on cardiac function in adult $\mathrm{GH}$ deficient patients. Scand J Clin Lab Inv 2012; 72: 387-394

[31] Berg C, Petersenn S, Walensi M et al. Cardiac risk in patients with treatment naïve, first-line medically controlled and first-line surgically cured acromegaly in comparison to matched data from the general population. Exp Clin Endocrinol Diabetes 2013; 121: 125-132

[32] Ronchi CL, Varca V, Beck-Peccoz P et al. Comparison between six-year therapy with long-acting somatostatin analogs and successful surgery in acromegaly: effects on cardiovascular risk factors. J Clin Endocr Metab 2006; 91: 121-128

[33] Colao A, Pivonello R, Galderisi M et al. Impact of treating acromegaly first with surgery or somatostatin analogs on cardiomyopathy. J Clin Endocr Metab 2008; 93: 2639-2646 